\title{
STUDI KEBUTUHAN BUKAAN \\ PADA BANGUNAN PERUMAHAN TYPE MENENGAH \\ DENGAN PENDEKATAN PENCAHAYAAN
}

\section{Ode Rapija GW}

Jurusan Teknik Sipil-Fakultas Teknik Universitas Muhammadiyah Malang Jl. Raya Tlogomas 246 Malang 65144

Email : odewaibo@yahoo.com

\section{ABSTRACT}

The purpose of the light on the environment is to lightening every element of the building which makes the clearer visual sence. In addition, the presence of the light is hoped to comfort the person who lives there which their activities. The building on medium size (type 45 and type 54) has the small window. Moreover, the building placed on the block only has the front window. It causes the building on medium size will catch less light, the room will be darker, and the lamp will be turned on the day.

The instrument of this research is a software dialux 4,7 . The advantages of using this software dialux 4, 7 are it will be easier and more variative in editing the geometry of the room, it will be easier in inserting the furniture to the room which will be calculated, and the output can be conturgrid-3d. The size of the windows in the guestroom, the family room, and the diningroom of the
medium building is about $4,09-5,6 \mathrm{~m}^{2}$. The window in the main bedroom is about $1,51-1,96 \mathrm{~m}^{2}$ width. The window in the children bedroom is about $1,38-1,64 \mathrm{~m}^{2}$ width.

Keywords: window, lightening intensity.

\section{PENDAHULUAN}

Kehadiran cahaya pada lingkungan bertujuan menyinari berbagai bentuk elemen-elemen yang ad pada bangunan sehingga ruang menjadi teramati dengan jelas seakan terasakan suasana visualnya (visual sense). Selain itu kehadiran cahaya juga diharapkan dapat membantu pemakai ruang untuk dapat melakukan aktifitasnya dengan baik dan merasa nyaman.

\section{Background}

Perancangan penerangan alami yang tepat adalah memasukkan radiasi matahari berupa cahaya pantulan kedalam ruangan dengan jumlah dan propors yang tepat dalam takaran kenyamanan secara visual. Cahaya dan terang alami merupakan prasyarat penting dalam penerangan alami. Cahaya terang sendiri dipengaruhi oleh bidang edar matahari sebagai sumber cahaya yang berdampak pada kondisi terang pada

Ode Rapija GW, Studi Kebutuhan Bukaan Pada Bangunan Perumahan Type Menengah Dengan | 35

Pendekatan Pencahayaan

kubah langit, sistim penyinaran, karakter ruangan serta persepsi pemakai terhadap cahaya alami.

Sebagai sumber cahaya, matahari, dan keberadaan matahari di Indonesia yang beriklim tropis sangat mempengaruhi bidang bukaan (jendela) Karakter ruang, bentuk bangunan dan tipologi bangunan. Bangunan membutuhkan cahaya matahari yang cukup pada siang hari, dan penggunaan lampu perlu dihindari untuk penghematan energi listrik.

Pada bangunan perumahan tipe menengah (tipe 45 dan 54), bukaan pada dinding relative kecil, apalagi rumah yang terletak di tengah blok, relative bukaan hanya pada bagian depan bangunan. Hal ini menyebabkan cahaya yang masuk ke dalam rumah tipe menengah relatifkurang, ruang menjadi agak gelap sehingga lampu sering dinyalakan pada siang hari. Kondisi tersebut di atas membutuhkan perencanaan yang baik. Pendekatan penelitian ini adalah melalu pola rasionalis dan pola empiris. Penggabungan pendekatan induktif dan deduktif, untuk mengatasi kelemahan pendekatan ini dilakukan pengujian berulang-ulang dalam rancangan penelitian. Proses 
penelitian memerlukan software DIALUX. Melalui simulasi akan dapat diketahui bukaan yang tepat untuk rumah tipe menengah.

Adapun cara penelitian secara lengkap dapa dilihat pada diagram 1 di bawah ini. Hasil simulasi berupa

\section{METODELOGI PENELITIAN}

a. cara penelitian

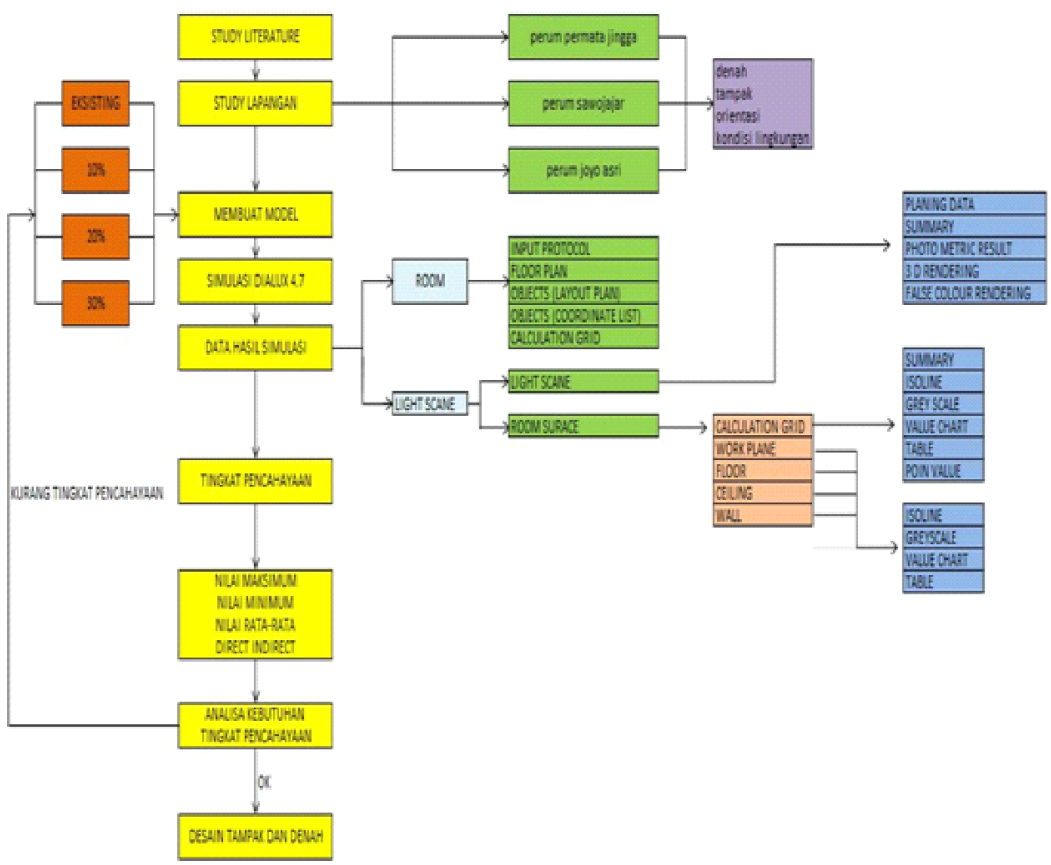

Gambar 1. Kerangka penelitian

\section{b. Alat Penelitian}

Dalam penelitian ini instrument penelitian yang digunakan berupa software. Software yang digunakan untuk simulasi ini adalah dialux 4,7. Adapun kelebihan dari software dialux 4,7 adalah sebagai berikut:

a. Yang digunakan tampilan dengan window

b. Edit geometri ruang dapat dibuat sangat variatif dan mudah

c. Insert furniture bisa dilakukan kedalam ruang

yang akan dicalculation

36 |Media Teknik Sipil, Volume 10, Nomor 1, Februari 2012: 35 - 40

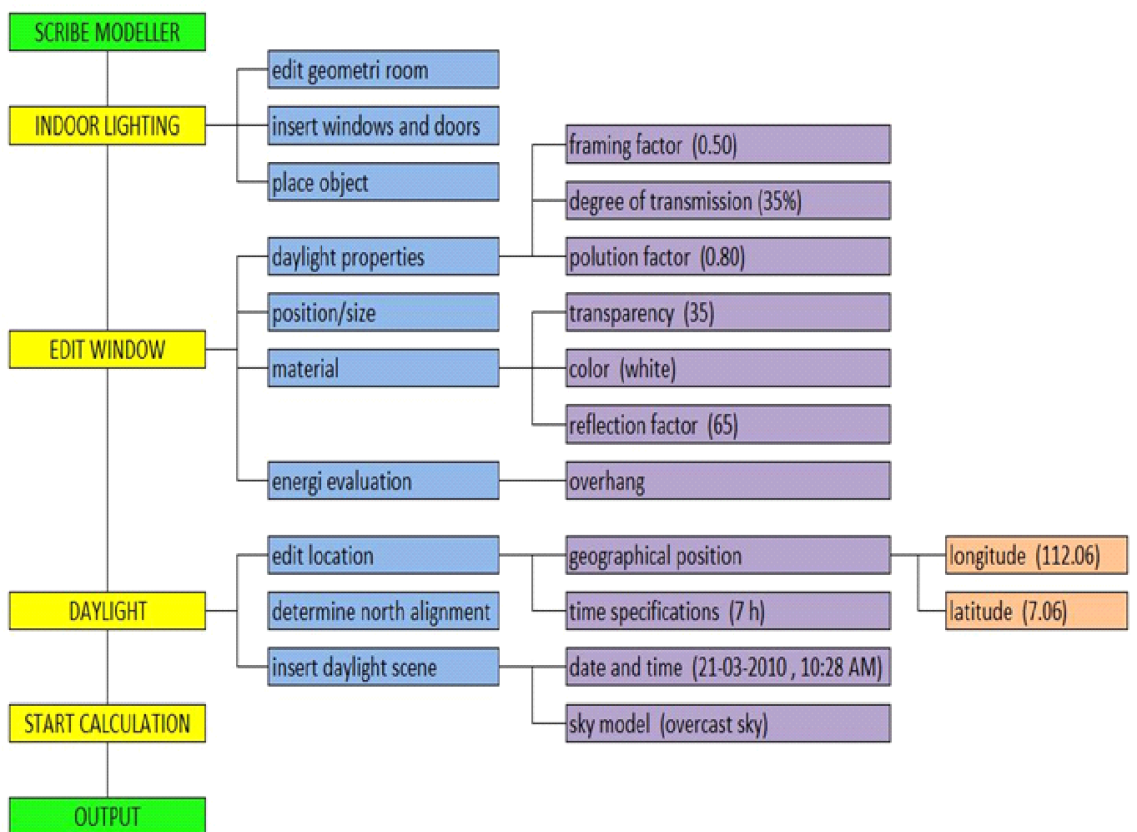

Gambar 2.. Struktur Program Dialux 4.7

\section{c. Konsep Penelitian}

Dimana jika tingkat pencahayaan masih tidak memenuhi persyaratan yang ditentukan maka akan ditambah luas bukaan setiap 10\% hingga mencukup tingkat pencahayaan.

Pada penelitian ini dilakukan simulasi pada kondis eksisting, jika tingkat pencahayaan rata-rata masih belum mencukupi dilakukan penambahan luas bukaan $10 \%$ dari kondisi eksisting dan bila tidak mencukupi ditambah 20\% lagi dari kondisi eksisting. Begitu pula jika masih belum mencukupi akan ditambah 30\% dari kondisi eksisting. Akan tetapi jika pada kondisi eksisting atau penambahan $10 \%$ atau $20 \%$ atau $30 \%$ sudah mencukupi maka tidak akan ditambah luas bukaannya. Hal ini akan dilakukan pada ruang utama, kamar tidur utama dan kamar tidur anak.

Tabel 1. Konsep penambahan luas bukaan

\begin{tabular}{lc}
\hline Nama Ruang & KONDISI \\
& BUKAAN \\
\hline R.Utama & Existing \\
& $10 \%$ \\
& $20 \%$ \\
& $30 \%$ \\
\hline R. Tidur Utama & Existing \\
& $10 \%$ \\
& $20 \%$ \\
& $30 \%$ \\
\hline R. Tidur Anak & Existing \\
& $10 \%$ \\
& $20 \%$ \\
& $30 \%$ \\
\hline
\end{tabular}

Ode Rapija GW, Studi Kebutuhan Bukaan Pada Bangunan Perumahan Type Menengah Dengan $\mid 37$ Pendekatan Pencahayaan 


\section{HASIL DAN PEMBAHASAN}

Lokasi penelitian berada di kota Malang yang Perumahan permatajingga terletak pada $112,06^{\circ}-12,07^{\circ}$ bujur timur dan $7,06^{\circ}$ $8,02^{\circ}$ lintang selatan, perumahan yang dipilih antara

b. Perumahan sawojajar

c. Perumahan joyoasri

Informasi yang didapat dari lokasi penelitian akan menjadi sumber data, dengan data tersebut akan dilakukan simulasi menggunakan dialux 4,7 IV.26): a. Perumahan permatajingga

Perumahan permatajingga ini mempuyai arah menghadap utara-selatan, dari hasil simulasi yang telah dilakukan di dapatkan hasil sebagai berikut (lihat tabel

Pada ruang utama yaitu ruang tamu, ruang makan, dan ruang keluarga dibutuhkan luas bkæan5,6matau penambahan $20 \%$ dari kondis eksisting untuk mendapatkan tingkat pencahayaan rata-rata 126 lux.

Tabel 2. Tingkat pencahayaan di perumahan permatajingga

\begin{tabular}{clcccc}
\hline \multirow{2}{*}{$\begin{array}{c}\text { nama } \\
\text { ruang }\end{array}$} & kondisi & luas bukaan & \multicolumn{3}{c}{ tingkat pencahayaan pada workplan } \\
\cline { 4 - 6 } & bukaan & $\left(\mathrm{m}^{2}\right)$ & maksimum (lux) & minimum (lux) & rata-rata (lux) \\
\hline R.utama & existing & 4.68 & 990 & 12 & 109 \\
& $10 \%$ & 5.14 & 1023 & 13 & 118 \\
& $20 \%$ & 5.6 & 1024 & 13 & 126 \\
\hline R.tidur & existing & 1.5 & 976 & 7.82 & 98 \\
utama & $10 \%$ & 1.65 & 988 & 8.83 & 107 \\
& $20 \%$ & 1.8 & 990 & 9.54 & 118 \\
& $30 \%$ & 1.96 & 1008 & 10 & 126 \\
\hline R.tidur anak & existing & 4.9 & 1183 & 62 & 326 \\
\hline
\end{tabular}

Pada ruang tidur utama dibutuhkan luas bukaan $1,96 \mathrm{~m}^{2}$ atau penambahan $30 \%$ dari kondisi eksisting untuk mendapatkan tingkat pencahayaan rata-rata 126 lux.

Perumahan sawojajar ini mempuyai ara menghadap utara-selatan, dari hasil simulasi yang telah dilakukan seperti pada tabel IV.27. di dapatkan hasi sebagai berikut:

Pada ruang tidur anak dengan luas bukaan 4,9

Pada ruang utama yaitu ruang tamu, ruang $\mathrm{m}^{2}$ atau sesuai kondisi eksisting didapatkan makan, din bukaan $4.09 \mathrm{~m}^{2}$ atau penambahan $10 \%$ dari kondisi eksisting untuk mendapatkan tingkat pencahayaan rata-rata 126 lux.

Perumahan sawojajar

Tabel 3. Tingkat pencahayaan di perumahan sawojajar

\begin{tabular}{clcccc}
\hline nama & kondisi & luas bukaan & \multicolumn{3}{c}{ tingkat pencahayaan pada workplan } \\
\cline { 4 - 6 } \multicolumn{1}{c}{ ruang } & bukaan & & $\begin{array}{c}\text { maksimum } \\
\text { (lux) }\end{array}$ & minimum (lux) & rata-rata (lux) \\
\hline R.utama & existing & 3.72 & 898 & 10 & 112 \\
& $10 \%$ & 4.09 & 901 & 11 & 126 \\
R.tidur & existing & 1.26 & 747 & 7.33 & 101 \\
utama & $10 \%$ & 1.38 & 963 & 7.48 & 111 \\
& $20 \%$ & 1.51 & 979 & 7.83 & 121 \\
R.tidur anak & existing & 1.26 & 964 & 7.22 & 110 \\
& $10 \%$ & 1.38 & 982 & 7.88 & 122 \\
\hline
\end{tabular}

38 |Media Teknik Sipil, Volume 10, Nomor 1, Februari 2012: 35 - 40
Pada ruang tidur utama dibutuhkan luas bukaan dilakukan di dapatkan hasil sebagai berikut (lihat tabel $1,51 \mathrm{~m}^{2}$ atau penambahan $20 \%$ dari kondisi IV.28):

eksisting untuk mendapatkan tingkat pencahayaan rata-rata 121 lux.

Pada ruang tidur anak dengan luas bukaan 1.38 $\mathrm{m}^{2}$ atau penambahan $10 \%$ dari kondisi eksisting untuk mendapatkan tingkat pencahayaan ratarata 122 lux.

Pada ruang utama yaitu ruang tamu, ruang makan, dan ruang keluarga dibutuhkan luas bukaan $4.55 \mathrm{~m}^{2}$ atau penambahan $30 \%$ dari kondisi eksisting untuk mendapatkan tingkat pencahayaan rata-rata 128 lux

\section{Perumahan joyoasri}

Perumahan joyoasri ini mempuyai arah menghadap timur - barat, dari hasil simulasi yang telah

Tabel 4. Tingkat pencahayaan di perumahan joyoasri

\begin{tabular}{lccccc}
\hline nama & kondisi & luas bukaan & \multicolumn{3}{c}{ tingkat pencahayaan pada workplan } \\
\cline { 3 - 6 } ruang & bukaan & & $\begin{array}{c}\text { maksimum } \\
(\text { lux) }\end{array}$ & minimum (lux) & rata-rata (lux) \\
\hline R.utama existing & 3.5 & 953 & 5.19 & 90 \\
& $10 \%$ & 3.85 & 955 & 5.94 & 103 \\
$20 \%$ & 4.2 & 960 & 8.04 & 118 \\
& $30 \%$ & 4.55 & 962 & 9.21 & 128 \\
R.tidur & existing & 1.25 & 482 & 8.59 & 101 \\
utama & $10 \%$ & 1.38 & 504 & 9.29 & 111 \\
& $20 \%$ & 1.51 & 532 & 9.73 & 121 \\
R.tidur & existing & 1.25 & 476 & 11 & 92 \\
anak & $10 \%$ & 1.38 & 507 & 11 & 101 \\
& $20 \%$ & 1.51 & 532 & 12 & 110 \\
& $30 \%$ & 1.64 & 551 & 12 & 121 \\
\hline
\end{tabular}

Pada ruang tidur utama dibutuhkan luas bukaan $1,51 \mathrm{~m}^{2}$ atau penambahan $20 \%$ dari kondisi eksisting untuk mendapatkan tingkat pencahayaan rata-rata 121 lux.

Pada ruang tidur anak dengan luas bukaan 1.64 $\mathrm{m}^{2}$ atau penambahan $30 \%$ dari kondisi eksisting untuk mendapatkan tingkat pencahayaan ratarata 121 lux.

\section{KESIMPULAN DAN SARAN}

Berdasarkan hasil penelitian dan pembahasan yang telah diuraikan, maka dalam penelitian in diperoleh beberapa kesimpulan sebagai berikut :

a. Bentuk denah dan tampak pada peru permatajingoa, sawojajor danjoyoasi dapat dipertankan, hanya luas bukaan yang perlu ditambah hingga $30 \%$.

b. Bukaan untuk ruang utama berupa ruang tamu, ruang keluarga, ruang makan untuk rumah menengah luas bukaan antara $4.09-5,6 \mathrm{~m}^{2}$ c. Ruang tidurutama dibutuhkan bukaan seluas $1,51-1,96 \mathrm{~m}^{2}$.

d. Bukaan untuk ruang tidur anak luas bukaan $1,38-1.64 \mathrm{~m}^{2}$.

\section{DAFTAR PUSTAKA}

Bockott, HE, GodFrey, JA . (1974), Window, Performance, Design, And Installation, Van Nostrand Reinhold, New York.

Brown, G.Z. (1987) Sun, Wind, and Light, Alih Bahasa Aris K.O, Intermatra, Bandung.

Ode Rapija GW, Studi Kebutuhan Bukaan Pada Bangunan Perumahan Type Menengah Dengan | 39 Pendekatan Pencahayaan 
Brown, G.Z. \& Mark DeKay (2001), Sun, Wind and Light, Architectural Design Strategies. John Wiley and Sons.

Djunaedi, Achmad (1989). Pengantar Metodologi Penelitian Arsitektural. Jurusan Teknik Arsitektur Fakultas Teknik. Universitas Gajah Mada Yogyakarta

Egan, DM., (1983), Concepts in Architectural Lighting Mc Graw Hill Books Company, New York.

Evan, B.H: Daylight in Architechture, Architectural Record Books Mc. Graw-Hill Book Company, New York,

Hopkinson, RG; Kay, JD. (1968) The Lighting of Building, , Fabor, London.

http://www.archlighting.com/architecturallighting/ images/pdf/Lincoln_Web.pdf

http://www.light-creation.co.jp/Architectural-l-e.html Juwana, Jimmy S. (2005). Panduan Bangunan Tinggi Untuk Arsitek dan Praktisi Bangunan. Jakarta: Penerbit Erlangga.

Koenigsberger, Ingersoll, Mayhew, Szokolay (1973), Manual of Tropical Housing and Building, Part 1. Climatic Design. Longman Group.

Lam, William M.C (1977), Perception and Lighting as Formgivers for Architecture. Van Nostrad Reinhold : NewYork.

Lam, William M.C (1986), Sunlight as Formgivers for Architecture. McGraw-Hill.

Mangunwijaya, YB (2000), Pengantar Fisika Bangunan. Penerbit Djambatan, Jakarta.

Nazir, Moh. Ph.d. (1988). Metode Penelitian. Jakarta: Penerbit Ghalia Indonesia.

Santosa, M (1985) Building Science And Architectureal Science, Department of Architecture, Faculty of Civil Engineering and

40 |Media Teknik Sipil, Volume 10, Nomor 1, Februari 2012: 35 - 40
Planning, Sepuluh Nopember Institute of Technology, Surabaya.

Seminar Studi Kemungkinan Transformasi Konsep Richard Meier Ke Dalam Arsitektur Tropis Indonesia

Serial Rumah.2005. Lighting-Percantik Interior \& Eksterior. Jakarta : PT Prima Infosarana Media.

SP Honggowidjaja (2000), Jurnal Pengaruh Signifikansi Tata Cahaya pada Desain Interior, Staf Pengajar Fakultas Seni dan Desain, Jurusan Desain Interior Universitas Kristen Petra Surabaya.

Wilkes, Joseph A (1988). Envelopes, Building. Encyclopedia of Architecture: Design, Engineering \& Construction. Vol.2. Jon Wiley Son

Wilkes, Joseph A. (1988). Atrium Buildings. Encyclopedia of Architecture: Design Engineering \& Construction. Vol.1. Wiley.

Wilkes, Joseph A. (1988). Lighting-daylighting. Encyclopedia of Architecture: Design, Engineering \& Construction. Vol.3. Wiley. 